\title{
Aquinas on the Problem of Universals
}

Jeffrey E. Brower, Purdue University

Aquinas's solution to the problem of universals has received a great deal of attention, both from historians and from non-historians alike. ${ }^{1}$ Even so, the proper understanding of his solution remains a hotly disputed question. Indeed, I think it's fair to say that debates on this score have reached an impasse - with some commentators classifying Aquinas as a realist, others classifying him as a nominalist, and yet others classifying him as something in between (say, as a moderate realist or conceptualist) or even as inconsistent. Brian Leftow provides a good sense of the controversy when he writes:

Aquinas' theory of attributes is one of the most obscure, controversial parts of his thought. There is no agreement even on so basic a matter as where he falls in the standard scheme of classifying such theories: to Copleston, he is a resemblance-nominalist; to Armstrong, a 'concept nominalist'; to Edwards and Spade, 'almost as strong a realist as Duns Scotus'; to Gracia, Pannier, and Sullivan, neither realist nor nominalist; to Hamlyn, the Middle Ages' 'prime exponent of realism,' although his theory adds elements of nominalism and 'conceptualism'; to Wolterstorff, just inconsistent. (Leftow 2003, p. 1) $^{2}$

The lack of consensus in these debates, as well as the sheer range of interpretations on offer, makes the proper understanding of Aquinas's views about universals all the more pressing. How are we to understand them? But they also raise a further, second-order question about their difficulty. Why are Aquinas's views on this issue so hard to classify?

\footnotetext{
${ }^{1}$ For Aquinas's works, I rely on the following abbreviations:

$D E E$

De ente et essentia

In DA Sententia super De anima

In Sent. $\quad$ Scriptum super libros Sententiarum

Quod. $\quad$ Quaestiones de quolibet

ST Summa theologiae
}

For editions of these works, see the bibliography. Unless otherwise indicated, all translations are mine.

${ }^{2}$ Leftow himself classifies Aquinas as a trope nominalist. 
In what follows, I propose answers to these questions. In particular, I offer a reconstruction of Aquinas's solution to the problem of universals that not only points a way out of the current interpretive impasse, but also helps to explain how we arrived at it in the first place. Part of the explanation, I will suggest, has to do with a failure to appreciate certain subtleties of Aquinas's own views. These views, though not unique to him, mark out a type of solution that has yet to be considered in the context of contemporary debates. A more important part of the explanation, however, has to do with a failure to appreciate certain subtleties of historical context. As I see it, the radical disagreement about the proper classification of Aquinas's solution owes to a tendency to conflate the medieval problem of universals with the problem that goes by that name in the contemporary literature. As it turns out, Aquinas's solution can be correctly classified in different ways, depending on which of the two problems we have in mind.

The remainder of the paper is divided into three parts. In the first part (Section 1), I offer a preliminary characterization of the medieval problem of universals, one that motivates the standard view about its connection to the contemporary problem. In the second part of the paper (Sections 2-3), I provide a reconstruction of Aquinas's solution to the medieval problem of universals. On the basis of this reconstruction, it will already be clear that the standard view about the relationship between the medieval and contemporary problems must be revised. In the third and final part of the paper (Section 4), I develop the necessary revision and spell out the implications for the proper classification of Aquinas's views.

\section{The Medieval Problem of Universals}

When medieval philosophers address the problem universals, it is natural to assume that they are addressing a version of the same problem at issue in contemporary debates. Indeed, it is 
typically assumed that both parties are addressing a single problem—what is often referred to simply as the problem of universals. In the context of contemporary debates, this problem is standardly described as that of providing an account of certain familiar facts of resemblance. ${ }^{3}$ To illustrate with a standard example, consider two human beings—-say, Socrates and Plato—who resemble color-wise. Insofar as they resemble in this respect, they are both members of a single class - say, the class of white things — and we can raise questions about their joint membership in the relevant class. Are we to explain or analyze this in terms of their sharing something in common? In particular, should we say that both individuals are members of the class of white things in virtue of possessing the universal whiteness? Or are we to account for their joint membership in the class in some other way—say, by taking it as primitive? ${ }^{4}$ To ask these sorts of questions just is to raise the contemporary problem of universals. And to answer them, in sufficient detail, is to propose a solution.

In order to facilitate comparison of this version of the problem with that at issue in medieval debates, it will be useful to restate the contemporary problem using some technical terminology. To this end, therefore, let us stipulate meanings for each of the following three terms - namely, kind, characteristic, and universal (or more precisely, universal characteristic):

(1) Kind $=_{\text {def }}$ any class of things whose members resemble one another in some respect.

(2) Characteristic $=_{\text {def }}$ whatever it is that locates a member in some kind (even if it is only the member itself or some primitive fact about it).

\footnotetext{
${ }^{3}$ The proper understanding of the contemporary problem of universals is not without controversy (see, e.g., Oliver 1996). But the description of the problem given in the text is now standard and owes in large part to the work of David Armstrong $(1979,1989)$ and David Lewis $(1983)$. As Lewis in particular emphasizes, the facts about resemblance that serve as the starting point for the contemporary problem of universals should be restricted to what Armstrong calls "Moorean facts" - that is, facts so familiar or well-known that they cannot reasonably be rejected. For further discussion of the contemporary problem of universals, as well as a detailed defense of this understanding of it, see Rodriguez-Pereyra 2000.

${ }^{4}$ As Lewis $(1983,252)$ reminds us in this context, taking a given fact as primitive is one perfectly acceptable way of providing an account:

Not every account is an analysis! A system that takes certain Moorean facts as primitive, as unanalysed, cannot be accused of failing to make a place for them. It neither shirks the compulsory question nor answers it by denial. It does give an account.
} 
Using this terminology, we can re-state the contemporary problem of universals in the form of a simple yes-or-no question, as well as distinguish the standard solutions in terms of the two main answers that can be given to it:

\section{The Contemporary Problem of Universals}

The problem:

$\circ \quad$ Are distinct things members of the same kind in virtue of sharing a universal?

The main solutions:

- Realism $=$ Yes, and hence there are universals.

- Nominalism $=$ No, because there are no universals.

There is more that could be said about the contemporary problem, but this statement of it will suffice for our purposes. ${ }^{5}$

Medieval philosophers have much to say about kinds and characteristics in the technical senses just defined. Even so, they tend to focus on specific sorts of each. Thus, instead of focusing on kinds in general, medievals tend to focus on species and genera — or what we might call natural kinds. And instead of focusing on characteristics in general, they tend to focus what we might call essential characteristics — or what they themselves call natures, or essences, or quiddities. Let us briefly consider what these further specifications come to.

We can capture the relevant notion of natural kind by thinking of it as a specific instance of the technical notion of kind defined above:

$$
\text { Natural kind }=_{d e f} \text { any kind whose members resemble one another in respect of what they are. }
$$

\footnotetext{
${ }^{5}$ It is perhaps worth noting that there is a type of realism - what we might call ostrich realism-that is often overlooked in discussions of the contemporary problem of universals, and hence is not included in my statement of it. According to this type of realism, ordinary facts about resemblance are not to be analyzed or explained in terms of any universals; on the contrary, they are to be taken as primitive. Like nominalists, therefore, ostrich realists provide a negative answer to the question posed by the contemporary problem. Unlike nominalists, however, such realists think universals must be appealed to in other contexts, to play other theoretical roles (e.g., to serve as referents or meanings of abstract singular terms). Although I shall hereafter ignore the complications raised by this type of realism, see van Inwagen 2011 for an example of someone who embraces it. Van Inwagen refers to himself as an 'ostrich Platonist' $(2011,398)$ on the grounds that he takes universals to be abstract entities or Platonic universals.
} 
To illustrate this notion, consider again our example involving Socrates and Plato. Earlier we noted that, in virtue of resembling color-wise, Socrates and Plato belong to the class of white things. But white things cannot be said to represent one of their natural kinds, precisely because it doesn't tell us what they are. On the contrary, it tells us something more like how they happen to be (and hence corresponds to what medievals would regard as one of their accidental kinds). To identify one of Socrates's and Plato's natural kinds, we must consider them insofar as they resemble human-wise, and hence insofar as they belong to the kind human beings. Or else we must consider them insofar as they resemble in some more general respect—say, animal-wise or body-wise or substance-wise - and hence insofar as they belong to some kind that subsumes human beings. For it is only insofar as Socrates and Plato resemble in one of these respects that they can be said to belong to a kind that tells us what they are-say, human beings, in the case of their species (or most specific natural kind), or animals, or bodies, or substances in the case of their genera (or some more general natural kind to which they belong). ${ }^{6}$

In addition to focusing on certain sorts of kinds — namely, natural kinds - medieval discussions of universals also tend to focus on certain sorts of characteristics — namely, those that locate things in their natural kinds. For obvious reasons, medievals refer to the characteristics in question as natures or essences - or even as quiddities, since they account for what a thing is (quid est). Here again, we can capture the relevant notion by thinking of it as a more specific instance of one of the technical notions defined above-in this case, characteristic:

(5) Nature (or essence) ${ }_{\text {def }}$ whatever it is that locates a member in some natural kind (even if it is only the member itself or some primitive fact about it).

\footnotetext{
${ }^{6}$ I'm ignoring here certain complications associated with what the medievals call differentiae, which might also be thought of as marking out natural kinds.
} 
It is important to emphasize just how open-ended, or functional, this notion is. ${ }^{7}$ In contemporary discussions, natures or essences are often conceived of as entities of a specific ontological type or category—namely, abstract entities or Platonic universals. But in medieval discussions, the same is not true. Medieval philosophers generally assume that natures or essences are somehow immanent to, or constituent parts of, their possessors. But beyond that, they take no stand on their precise nature or ontological status — or for that matter, even on their precise relationship to their possessors. Socrates must be said to have a nature or essence, humanity, in virtue of which he belongs to the species human beings, and likewise for Plato. Even so, it is an open question for medieval philosophers whether Socrates's humanity is distinct from Plato's, and indeed, whether such "humanities" are distinct from Socrates and Plato themselves. ${ }^{8}$

We are now, finally, in a position to state the medieval problem of universals in a way that will enable us to begin reflecting on its relationship to the contemporary problem:

\section{The Medieval Problem of Universals-Preliminary Characterization}

The problem:

$\circ \quad$ Are distinct things members of the same natural kind in virtue of sharing a common nature?

The main solutions:

$\circ \quad$ Realism $=$ Yes, and hence there are common natures.

$\circ \quad$ Nominalism $=$ No, because there are no common natures.

It will be noticed that I have stated the problem here in terms of common natures rather than universals (or universal natures). ${ }^{9}$ This way of stating the problem is intended not only to reflect the standard medieval terminology, but also to leave open the question of how precisely common

\footnotetext{
${ }^{7}$ As is perhaps obvious, none of the "definitions" given in this paper are to be understood in terms of what the medieval would call real (as opposed to nominal) definitions - that is, definitions in terms of genera and differentiae. On the contrary, they are merely intended to be necessarily co-extensive with the relevant definienda. ${ }^{8}$ See Klima 2013, and the references cited therein, for relevant background and discussion.

${ }^{9}$ Once again, I'm ignoring the possibility of any type of ostrich realism. But see Bulthius forthcoming for a medieval example of someone who may have embraced this type of realism-namely, Walter Burley (c. 12751344).
} 
natures are to be understood. ${ }^{10}$ It must be noted, however, that there appears to be at least some pressure, from medieval discussions themselves, to conceive of common natures as a type of universal—and this for at least three reasons.

First, it is hard to see what medievals could have in mind by a common nature, if not some type of universal. For common natures are taken to be the same for all their possessors. Indeed, I think it is fair to say that the following definition captures the standard medieval conception:

(6) Common nature $=_{\text {def }}$ a nature that is the same for all members of the same natural kind.

But how are we to understand this definition if not as a specific instance of the technical notion of universal defined earlier? The sense in which common natures are the same for all their possessors is not to be understood in terms of mere resemblance (what is sometimes called sameness in the "loose and popular" sense). On the contrary, it is to be understood in terms of a stricter sort of sameness that explains such resemblance (since even those medieval nominalists who reject common natures allow that things have resembling natures - more on this shortly). But what could it mean to say that Socrates's humanity is the same as Plato's humanity in a sense that is both (a) stronger than mere resemblance (and hence requires the existence of a common nature), but nonetheless (b) weaker than identity (and hence does not require the existence of a universal)?

\footnotetext{
${ }^{10}$ As is often noted in the secondary literature, 'common nature' (natura communis) comes to be a term of art in late medieval debates about universals, due in large part to the influence of Avicenna. See, e.g., Owens 1957. But it is important to emphasize that talk of common natures or essences was also prevalent in early medieval debates, due in large part to the influence of Boethius. It is, in fact, Boethius who is responsible for introducing the distinctively medieval problem of universals, and he not only frames this debate in terms of natures or essences (i.e., the characteristics that locate things in their genera and species) but also focuses on the sense which such natures or essences can be said to be "common to many". Indeed, he famously describes a real universal in terms of a single nature or essence that is common to many (i) as a whole, (ii) at the same time, and (iii) in such a way as to constitute the substance of its possessor. See his Second Commentary on Porphyry 1.10 (trs. Spade 1996, 22). See also Spade 1998,258, n. 11.
} 
Second, conceiving of common natures as universals helps to explain something else that would otherwise seem puzzling - namely, the preoccupation of medieval realists with questions about individuation. If common natures are conceived of as universals, this preoccupation makes perfect sense. For if Socrates's humanity is identical to Plato's humanity, then obviously something other than their common nature must be appealed to in order to explain their numerical distinction or individuality. And the need for such an appeal immediately invites further questions about what this principle of individuation might be.

Finally, the conception of common natures as universals seems to be required for the correct classification of paradigmatic forms of medieval realism and nominalism. Consider, for example, the so-called material essence realism of William Champeaux (c. 1070-1122). ${ }^{11}$ On this form of realism, natures or essences are said to be common precisely because they are universal. Hence individuals, such as Socrates and Plato, are conceived of as complexes consisting of their common nature, the universal humanity, plus distinct principles of individuation. ${ }^{12}$ Indeed, common natures or essences on this view are referred to as material precisely to indicate that they can be combined with distinct individuators to make distinct individuals in roughly the same way that a single portion of matter (on a broadly Aristotelian view) can be combined with distinct forms to make distinct hylomorphic compounds. ${ }^{13}$

\footnotetext{
${ }^{11}$ Much of what we know about Champeaux and his views is due to the influence of Peter Abelard. For helpful discussion, see Guilfoy 2008.

${ }^{12}$ Compare, e.g., Abelard's description of Champeaux's view in his Logica 'Ingredientibus': Some people take "universal thing" in such a way that they set up essentially the same substance in things diverse from one another through forms. This substance is the "material essence" of the singulars it is in. It is one in itself, and diverse only through the forms of its inferiors ... For example in single, numerically distinct men there is the same substance man, which becomes Plato here through these accidents and Socrates there through those accidents. (Spade 1994, 29-30)

${ }^{13}$ Again, compare the description in Abelard: Likewise, they also posit one and essentially the same substance animal in single animals that differ in species. They draw this substance into diverse species by taking on diverse differences. For example, if out of this wax I make on the one hand a statue of a man and on the other a statue of an ox, by adapting diverse forms to entirely the same essence that remains throughout.
} 
Again, consider the late medieval nominalism of William Ockham (c. 1287-1347). Just as Champeaux's realism about common natures entails the existence of universals, so too Ockham's nominalism entails their non-existence. Indeed, according to Ockham, natures are not only individual—so that Socrates's humanity is distinct from Plato's — but also identical to their possessors - so that Socrates is identical to his individual humanity and Plato is identical to his. ${ }^{14}$

In short, there appear to be a number of good reasons for thinking that the medieval notion of a common nature just is the notion of a specific type of universal—namely, a universal nature (i.e., a nature that is identical for all members of the same natural kind). Of course, if this were the right way to think about common natures, then the medieval problem of universals would turn out to be a version of the contemporary problem — in fact, it would just be the contemporary problem applied to a specific sort of characteristic. For reasons I will now explain, however, this is not the right way to think about either common natures or the medieval problem of universals. On the contrary, in each case things are much more complicated.

\section{Aquinas’s Solution to the Medieval Problem of Universals}

Aquinas's views about universals are interesting, in part, because they underscore the complicated relationship that obtains, for medievals, between universals and common natures. There can, I think, be little doubt that Aquinas explicitly rejects the existence of universals at

But it makes a difference in the example that the same ways does not make up the two statues at the same time, as is allowed in the case of a universal - that is, the universal is common, as Boethius says, in such a way that the same whole is at the same time in diverse things, of which it constitutes the substance materially. (Spade 1994, 30)

${ }^{14}$ See in particular Quodlibetal Questions 5.10-11 (trs. Freddoso and Kelly 1991, 433-41), where Ockham makes it clear that, apart from the special case of the Incarnation of Christ, every human being is identical to its individual humanity. Compare also Ockham's reply to the following objection in his commentary on Peter Lombard's Sentences:

Suppose someone says: Socrates and Plato really agree more than Socrates and an ass do. Therefore, Socrates and Plato agree in something real in which Socrates and an ass do not really agree ... I reply: Literally it should not be granted that Socrates and Plato agree in something or somethings, but that they agree by somethings, because they agree by themselves. (Spade 1994, 181) 
various places in his writings. At some places, moreover, his rejection of universals appears to take the form of a rejection of common natures. Consider, for example, the following passage from his commentary on Peter Lombard's Sentences:

Humanity is something that exists in reality, but there it is not universal. For no humanity that exists outside the mind (extra animam) is common to many. (In Sent 1.19.5.1)

Here Aquinas tells us that the nature in virtue of which Socrates and Plato belong to their species_-namely, humanity — is neither universal nor common. Indeed, Aquinas insists that this nature is not common precisely because it is not universal. The clear implication is that Socrates and Plato must each have their own distinct natures, an implication that Aquinas explicitly develops later in the same work:

Even if this individual [say, Socrates] is a human being and that individual [say, Plato] is a human being, it is not necessary that both have numerically the same humanity - any more than it is necessary for two white things to have numerically the same whiteness. On the contrary, it is necessary [only] that the one resemble the other in having [an individual] humanity just as the other does. It is for this reason that the mind - when it considers [an individual] humanity, not as belonging to this [or that] individual, but as such-forms a concept that is common to them all. (In Sent 2.17.1.1)

In this passage, Aquinas develops his views in a way that would appear to bring them in line with Ockham's nominalism an important respect. For Aquinas insists here that things are not members of the same natural kind in virtue of possessing numerically the same nature. On the contrary, they are members of the relevant kind by virtue of possessing distinct but resembling natures. No doubt, it is considerations like these that have led some commentators to describe Aquinas's views in terms of nominalism_ or even trope nominalism, since it is natural to think of individual natures as tropes (i.e., individual or non-universal properties). ${ }^{15}$

It is important to note, however, that Ockham himself would not have accepted the claim that Aquinas makes in the final sentence of this passage. On the contrary, in what is perhaps his

\footnotetext{
${ }^{15}$ Note, however, that this way of thinking about individual natures can be misleading in the case of particular medieval authors. In the case of Ockham, for example, individual natures are best thought of not as tropes, but as objects composed of concrete particulars (namely, prime matter) and tropes (namely, substantial forms). See again Ockham's Quodlibetal Questions 5.10-11 (trs. Freddoso and Kelly 1991).
} 
best-known discussion of universals, Ockham suggests that it is impossible to start from a single, individual nature and arrive at a concept that is common to all the members of the relevant kind - as if there were some of way selectively attending to (or "abstracting" away from everything except) Socrates's humanity alone that would enable us to form a concept applicable to all human beings. ${ }^{16}$ Presumably, it is considerations like these that have led other commentators to describe Aquinas's views in terms of conceptualism rather than nominalism (though this description strikes me as unfortunate, since it suggests that the resemblance between distinct natures is somehow mind-dependent). ${ }^{17}$

The two passages just considered serve to highlight two theses that are characteristic of Aquinas's views about universals throughout his entire career:

(T1) Natures are individual in reality (i.e., outside the mind).

(T2) Natures are universal in the mind.

Admittedly, in the passages just considered, Aquinas appears to develop these theses in a way that requires the rejection of common natures. But more often than not, he develops them in a way that seems to require the acceptance of common natures rather than their rejection. Indeed, his typical way of developing T1 and T2 requires us to attribute to him a further thesis: Natures are common both in reality and in the mind.

It is a familiar theme of Aquinas's work that individuals such as Socrates and Plato cannot be identified with their natures precisely because their natures include all and only what is common to the members of the relevant natural kind. ${ }^{18}$ For the same reason, Aquinas insists that Socrates

\footnotetext{
${ }^{16}$ See Ockham's criticism of Henry Harclay's position in Ordinatio 1.2.7 (translated in Spade 1994), as well as the discussion in Spade 1985, chap. 60, pp. 11-12. Elsewhere Ockham allows that one can form specific (but not general) natural kind concepts on the basis of acquaintance with a single, individual nature, though even in these cases he denies that there is any common nature that is being abstracted. See Quodlibetal Questions 1.13 (trs.

Freddoso and Kelly 1991, 63-68) and the discussion in Panaccio 2004, 9-11.

${ }_{17}^{17}$ See, e.g., Clark 1974 for the description of Aquinas's views as conceptualist.

${ }^{18} \mathrm{See}$ in particular DEE 2-4 and ST 1.3.3. In these two texts, Aquinas restricts the distinction between natural kinds and their members (or "supposita") to the class of material beings, denying that it can be applied to either God or the
} 
and Plato must themselves be conceived of as complexes consisting of a common nature, humanity, plus distinct principles of individuation. Indeed, it is only because their nature is common, and hence in need of individuation, that Aquinas thinks we can form a perfectly general concept of humanity by selectively attending to the nature of any single human being. Thus, as he says in one of his other commentaries, putting all these points together:

The individuation of the common nature in corporeal and material things comes from their corporeal matter, which is matter contained under determinate dimensions. The universal, by contrast, is arrived at through abstraction from this sort of matter and from the individuating material conditions. (In DA 2.12.5)

Aquinas expresses his views about individuation differently in different places. In this passage, he describes the principle of individuation in terms of matter under determinate dimensions. But elsewhere he describes it in terms of matter under indeterminate dimensions. The details needn't concern us now. ${ }^{19}$ The important point is that his appeal to individuators of any sort makes no sense apart from something like T3. Unless natures were common in reality (i.e., outside the mind), there would be no need to appeal to individuators to explain the distinction between Socrates and Plato. Indeed, Aquinas assumes that it the commonness of natures outside the mind that explains their commonness or universality in the mind. ${ }^{20}$

Aquinas's appeal to common natures and principles of individuation, in passages like this last one, would seem to bring his views closely in line with Champeaux's realism. For like

angels. In Quod. 2.2.2, however, Aquinas suggests that the distinction applies to all creatures, whether material or immaterial and hence must be extended to the angels. See Wippel 2000, esp. 238-53 for discussion of the complications raised by this latter text for Aquinas's views.

${ }^{19}$ See Wippel 2000, esp. 351-375, for details.

${ }^{20}$ In $D E E$ 3, Aquinas says that a natures or essences can be considered in two ways: either (1) in themselves or absolutely, or (2) insofar as they have being (or existence) in individuals. What is more, he insists that taken in the first way, natures or essences are neither one nor many, neither individual nor universal. But don't these claims rule out the possibility of natures being common outside the mind? It is hard to escape this conclusion if we take these claims to imply that natures have no unity or being in themselves. Although commentators have often accepted this implication (Owens 1957 is perhaps the most influential in this regard, but see also Gracia 1994 and Spade 1999), I think this is a mistake. Indeed, for reasons that will become clearer in the next section, I take these claims to imply not that natures as such lack any unity or being whatsoever, but only that they lack the specific type of unity associated with individuals - namely, numerical unity or being. For a very different interpretation of these claims, see Galuzzo 2004. 
Champeaux, Aquinas not only appeals to common natures and individuators, but also conceives of individuals such as Socrates and Plato as complexes of both. What is more, he even relies on a hylomorphic analogy to explain his views - though unlike Champeaux, he thinks of individuators as playing the role of matter and natures or essences as playing the role of forms (rather than vice versa). In light of these considerations, it is not surprising that some commentators are inclined to describe Aquinas's views in terms of some sort of realism. ${ }^{21}$ Moreover, it is undoubtedly the conjunction of all the considerations that we've examined so far that has led yet other commentators to describe Aquinas's views as incoherent. ${ }^{22}$ After all, how could the appeal to common natures and individuators possibly be combined with the rejection of universals?

It is important to see, however, that there is no formal inconsistency here. When Aquinas denies the existence of universals, he means to be denying the existence of natures that are common only in the sense of being numerically the same (or identical) for all members of the same kind. The denial of common natures in this sense, however, is perfectly consistent with existence of natures that are common in some other sense.

Of course, if something more than mere formal consistency is to be maintained, Aquinas owes us some explanation of this other sort of commonness. After all, what could such commonness amount to, if not numerical sameness or mere resemblance? What's more, in the absence of any universal natures, Aquinas also owes us some explanation of his appeal to individuators. For on the face of it, such an appeal would appear to be gratuitous. If Socrates's humanity is distinct from Plato's, what need is there to appeal to anything further to distinguish

\footnotetext{
${ }^{21}$ See Clark 1974 for the claim that some form of realism represents the traditional interpretation of Aquinas's views. See also Edwards 1985 and Spade 1998.

${ }^{22}$ See Wolterstorff 1970, 146.
} 
Socrates and Plato? Indeed, why not simply follow Ockham and identify Socrates and Plato with their individual humanities?

Aquinas has answers to these questions, but to see what they are, we must take a closer look at the similarities and differences between Champeaux's realism and Ockham's nominalism. For it is between these two extremes that we must ultimately locate Aquinas's solution to the medieval problem of universals.

\section{Making Sense of Aquinas's Via Media}

Perhaps the most obvious similarity between the views of Champeaux and Ockham is that they both take for granted the existence of natures of some sort. As we have seen, in the context of medieval debates about universals, natures are to be understood in broadly functional terms - namely, as entities (whatever they are in themselves) that locate things in kinds or classes whose members resemble in a certain respect. Since the resemblances associated with natures all have to do with the intrinsic character of the resembling things, we can describe the functional role of natures as that of accounting for a certain sort of intrinsic character-namely, one that has to do with what things are.

Although Champeaux and Ockham both take for granted the existence of natures, or entities playing the roles associated with them, they disagree about what type of entities natures are. According to Champeaux, the entities responsible for generating the relevant sort of intrinsic character are universals, whereas according to Ockham they are individuals. This is perhaps the most obvious difference between their views. But this difference is closely connected with another. Because Champeaux takes natures to be universals, he is forced to postulate individuators distinct from them. As in the case of natures, we can describe individuators in broadly functional terms - namely, as entities (whatever they are in themselves) that account for 
the numerical distinctness of individuals belonging to the same natural kind. Because Ockham takes natures themselves to be individual, he feels no need to postulate individuators distinct from natures. On the contrary, he assumes that natures themselves can play the individuating role that Champeaux is forced to assign to distinct entities.

In short, Champeaux and Ockham both agree that there are entities playing the following two types of functional role:

\section{Two Types of Functional Role}

The role of natures vs. individuators:

- Nature role: $x$ plays the nature role iff $x$ accounts for a certain type of intrinsic character (namely, what a thing is).

- Individuator role: $x$ plays the individuator role iff $x$ accounts for individuality or numerical distinctness.

Although Champeaux and Ockham agree that there are entities playing each of these two roles, they disagree about the number and types of entities that play them. Champeaux assumes that these roles are always played by distinct entities at least one of which is universal. Thus, in the case of Socrates and Plato, there is one entity responsible for generating what they are-namely, the universal humanity - and some further entities responsible for generating their numerical distinctness - namely, their individuators. As it turns out, Champeaux identifies individuators with accidental characteristics, which he also takes to be universal. For the same reason, he ultimately takes both natures and individuators to be entities of the same fundamental typenamely, universals. Even so, in particular cases, Champeaux assumes that the roles associated with natures and individuators are always played by distinct universals (namely, universal natures and universal accidents). ${ }^{23}$

\footnotetext{
${ }^{23}$ Note that all of this commits Champeaux to a distinctive type of bundle theory-indeed, a bundle theory of universals.
} 
By contrast, Ockham assumes that, in such cases, the roles associated with natures and individuators are always played by the very same entities. Indeed, because he denies the existence of universals, he assumes that they are always played by the very same individuals. Thus, in the case of Socrates, it is his humanity, the individual nature to which he is identical, that both determines what he is and accounts for his numerical distinction from all other human beings. And the same is true in the case of Plato or any other human being. ${ }^{24}$ In fact, it is precisely because Ockham takes individuals to be capable of playing each of these two functional roles that he feels no need to identify a principle of individuation distinct from natures.

With these clarifications in mind, we are now finally in a position to begin appreciating the precise relationship of Aquinas's views to those of Champeaux and Ockham.

Note first that, for Aquinas, the roles of natures and individuators are always played by distinct entities. In this respect, his views are like those of Champeaux. Unlike Champeaux, however, Aquinas denies the existence of universals. For the same reason, he assumes that the roles of natures and individuators are always be played by individuals or non-universal entities. In this respect, his views are more like those of Ockham. But insofar as Aquinas identifies individuators with some sort of corporeal matter, his views would appear to be unlike either Champeaux's or Ockham's. For even if such matter is individual or non-universal, it would appear to be of a fundamentally different type than the natures it individuates. ${ }^{25}$

\footnotetext{
${ }^{24}$ Ockham's views about the Incarnation of Christ raise some complications for this claim, but we can ignore them here. See again the references cited in n. 14 above.

${ }^{25}$ Elsewhere I have argued that Aquinas is committed to a distinctive type of substratum theory, one in which portions of prime matter play the role of substrata that are ultimately responsible for individuation. Although portions of prime matter must be conceived of as non-universal, and can be conceived of as individual, I argue that they are best understood for Aquinas in terms of portions of non-individual stuff. See Brower 2014, esp. chs 5-6.
} 
However that may be, what is puzzling about Aquinas's views is his appeal to individuators of any sort. If natures are themselves individual, what need is there for anything to individuate them? Here is where the distinction between the two different functional roles becomes important. Unlike Ockham, Aquinas thinks that the entities playing the role of natures are not suited to play the role of individuators. And that is because, unlike Ockham, Aquinas does not conceive of individual natures as numerically distinct from one another in and of themselves. On the contrary, he thinks that they owe their numerical distinctness to something else - namely, to some other beings or entities that are numerically distinct in and of themselves, and hence suited to play the role of individuators. This last point is crucial, because it helps us to see that Aquinas is assuming that there are different ways in which things can be numerically distinct. Indeed, I think it is helpful to distinguish on his behalf two different types of numerical distinctness:

\section{Two Types of Numerical Distinctness}

Primitive vs. derivative distinctness:

- Primitive distinctness: $x$ is primitively distinct from $y$ iff $x$ is numerically distinct from $y$ in and of itself (i.e., the source of $x$ 's numerical distinctness from $y$ is internal to $x$ ).

- Derivative distinctness: $x$ is derivatively distinct from $y$ iff $x$ is numerically distinct from $y$ but not in and of itself (i.e., the source of $x$ 's numerical distinction from $y$ is not internal to $x$ ).

Both Ockham and Aquinas take for granted that Socrates and Plato possess numerically distinct individual natures. Indeed, they both take for granted that Socrates's and Plato's humanities are not only numerically distinct, but exactly resembling individuals; they are, we might say, exact duplicates of one another, and hence do not differ intrinsically in anyway. Even so, Ockham assumes, these two natures are primitively distinct. That is, the source of their distinctness must be traced to the natures themselves. On Ockham's conception, therefore, the distinction between Socrates's and Plato's humanities is like that between two bare particulars (or two points of spacetime). This is not the case for Aquinas. On the contrary, he assumes that 
Socrates's and Plato's humanities are merely derivatively distinct, and hence that the source of their distinctness must be sought outside them (namely, in their individuators). On Aquinas's conception, therefore, there is a distinctive type of sameness relation — what we might call internal sameness — holding between such natures. For although Socrates's and Plato's humanities are numerically distinct, they do not differ in themselves in any way; on the contrary, they are like two tropes that differ solely in virtue of being related to distinct bare particulars (or points of spacetime). ${ }^{26}$

As it turns out, the notion of internal sameness provides us with all we need to make sense of Aquinas's talk of common natures. Indeed, if we help ourselves to our earlier distinction between different types of numerical distinctness, we can make precise his understanding of the difference between common vs. universal natures in terms of the different types of sameness associated with each:

\section{Common vs. Universal Natures}

Two types of sameness:

- Numerical sameness: $x$ is numerically the same as $y$ iff $x=y$.

- Internal sameness: $x$ is internally the same as $y$ iff either (a) $x=y$, or (b) $x$ and $y$ are merely derivatively numerically distinct.

Two types of nature:

$\circ \quad$ Universal nature ${ }_{\text {def }}$ a nature that is identical for all members of the same natural kind.

- Common nature $=_{\text {def }}$ a nature that is internally the same (but not necessarily identical) for all members of the same natural kind.

In order to bring out the significance of all of this for Aquinas's solution to the medieval problem of universals, let us return one final time to the comparison of his views with those of Champeaux and Ockham. Consider, therefore, the following diagram, which contrasts their respective views of species membership for the particular case of Socrates and Plato:

\footnotetext{
${ }^{26}$ As the foregoing helps to make clear, the notion of internal sameness is stronger than that of intrinsic sameness. For even things that are intrinsically the same can be internally different. What is more, internal sameness is presumably not a relation that could hold between things merely contingently.
} 


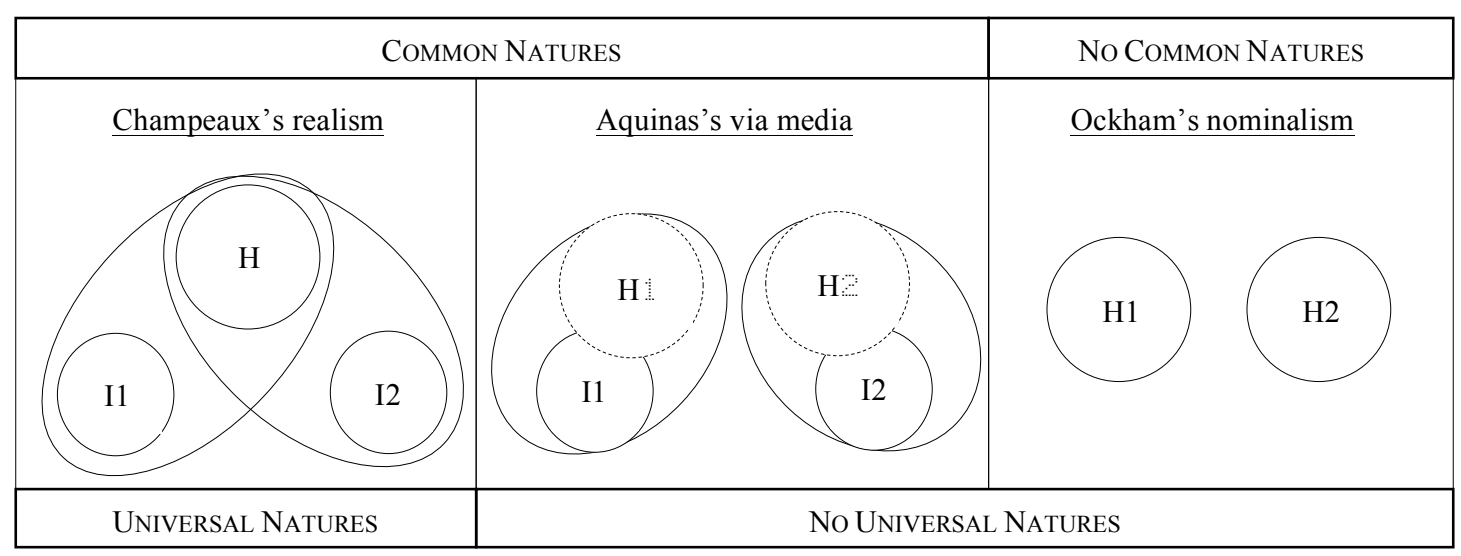

The circles in this diagram represent natures and individuators- - with ' $\mathrm{H}$ ' standing for 'humanity' and 'I' standing for 'individuator' — and the ovals represent complexes that include both natures and individuators as constituents. A circle without a numeral represents a universal, whereas a circle with a numeral represents an individual — with ' 1 ' being associated with Socrates and '2' being associated with Plato. Finally, a circle containing a numeral and surrounded by a solid line represents a primitively distinct individual, whereas a circle containing a numeral and surrounded by a dotted line represents a merely derivatively distinct individual. (In order to emphasize the fact that the individuation of derivatively distinct individuals traces to something wholly external, I have also used dotted text for the numerals they contain.)

As this diagram indicates, Aquinas's views are intended to steer a middle course between Champeaux's realism and Ockham's nominalism. Like Ockham, Aquinas rejects the existence of universals, and hence thinks of Socrates's and Plato's humanities as distinct individuals. But unlike Ockham, he does not think of them as primitively distinct. On the contrary, like Champeaux, he thinks of such natures as internally the same, and hence in need of individuation. For the same reason, he conceives of Socrates and Plato themselves as complexes of natures and individuators. 
There can be no doubt that Aquinas's views are, in certain ways, more complicated than both Champeaux's and Ockham's. But it is not hard to see why Aquinas would be willing to introduce such complications, especially if we think of his views as calculated to avoid certain costs, as well as to preserve certain benefits, of his competitors' views. For by denying the existence of universals, Aquinas is able to avoid what is perhaps the chief cost of Champeaux's realism - namely, the postulation of a type of entity that is often thought to be ontologically objectionable. ${ }^{27}$ Indeed, in this respect, Aquinas is able to retain something of the theoretical parsimony of Ockham's nominalism — namely, an account of kind membership solely in terms of individuals. Of course, Aquinas adds to his ontology a subtype or subcategory of individuals unrecognized by Ockham's nominalism—namely, derivatively distinct individuals. But his doing so is precisely what enables him to preserve some of the chief advantages of Champeaux's realism. For by appealing to such individuals, Aquinas is able to avoid taking the resemblance between Socrates and Plato as primitive; indeed, like Champeaux, he can analyze or explain such resemblance in terms of their sharing internally the same nature. ${ }^{28}$ What is more, appealing to derivatively distinct individuals also gives Aquinas a clear explanation of something else that might seem difficult, if not impossible, to explain on any form of nominalism — namely, our ability to get before our minds common natures or characteristics such as humanity. To do this, Aquinas thinks, we need only consider the nature of a given human being apart from its individuator, and this will automatically provide us with something that does not differ internally from the nature of any other human being. ${ }^{29}$

\footnotetext{
${ }^{27}$ See Oliver 1996 for a survey of the standard objections to universals.

${ }^{28}$ See Armstrong 1989, esp. 102-3, 136-39, for a defense of realism that emphasizes its ability to analyze or explain ordinary facts of resemblance. But see also van Inwagen 2011 for some grounds for skepticism regarding realism's explanatory value in this regard.

${ }^{29}$ See Wolterstorff 1970, esp. ch. 6, for a defense of realism that emphasizes its ability to explain how we can get before our minds common natures or characteristics. Although Wolterstorff explicitly considers and rejects
} 
In the end, I think it's clear that Aquinas's views mark out a distinctive type of solution to the medieval problem of universals, one whose subtlety and sophistication make it easy to overlook. Indeed, I think it is best thought as a type of trope theory whose virtues have yet to be appreciated in the contemporary context—namely, one according to which tropes are conceived of as derivatively (rather than primitively) distinct individuals, and for that very reason are taken to bear a distinctive type of sameness relation to one another (namely, mere internal sameness). ${ }^{30}$ In saying, this I don't mean to suggest that this type of solution is somehow unique to Aquinas. On the contrary, I think there are earlier medieval anticipations, as well as later medieval developments of it. ${ }^{31}$ But regardless of how widespread this type of solution was during the Middle Ages, I also think it is clear that the medieval problem in response to which it is developed is subtly though importantly different from the contemporary problem of universals. Before concluding, therefore, I want to return briefly to the relationship between these two problems, since appreciating their precise connection will enable us to understand why Aquinas's solution has been so hard to classify historically.

\footnotetext{
Aquinas's account of common natures as incoherent, his argument overlooks the possibility of distinct individuals that are internally the same.

${ }^{30}$ It is worth noting that my interpretation of Aquinas has some important similarities to that of Leftow, who also interprets Aquinas as holding a type of trope theory (see again n. 2). But whereas Leftow's interpretation can be thought of as supplementing the usual conception tropes (as primitively distinct individuals) with a primitive relation of sameness, my interpretation is best thought as introducing a new conception of tropes (as derivatively distinct individuals), in terms of which we can analyze or explain the distinctive type of sameness relation that such entities bear to one another (namely, internal sameness).

31 Aquinas's views can be (and have been) regarded as a natural development of the sort of position that Boethius develops in his influential discussion of Porphyry's Isagoge. See, e.g., McInerny 1990. They also bear an important similarity to early medieval forms of indifference realism. See Guilfoy 2008 for Champeaux's own development of this sort of position. Finally, Aquinas's views seems to me very similar to a position held by many later medieval philosophers and theologians, including Scotus and his followers, who aptly refer to the type of sameness associated with common natures as a less than numerical sameness (or unity). For a helpful discussion of Scotus's position, which is similar in many ways to my understanding of Aquinas's, see Hawthorne 1999. For a very different understanding of Scotus's position, one which sharply distinguishes it from Aquinas's, see Owens 1957.
} 


\section{The Medieval Problem of Universals Revisited}

Earlier I noted a respect in which the medieval problem of universals is clearly narrower than its contemporary counterpart. The contemporary problem focuses on characteristics and kinds in general, whereas the medieval problem focuses specifically on natures and natural kinds - where natures just are characteristics that locate things in natural kinds. If this were the only difference between the two problems, then their difference would be pretty insignificant. For as I also noted earlier, medievals have much to say about other sorts of characteristics and kinds, even if they are not the primary focus of their discussion of universals. Indeed, they typically just take their views about common natures or essences to generalize to characteristics associated with the members of any kind. ${ }^{32}$

As Aquinas's views help us to see, however, this is not the only difference between the two problems. On the contrary, there is also a respect in which the medieval problem is clearly the broader of the two. Both problems are obviously concerned, at some level, with the same question - namely, whether things are members of the same kind in virtue of possessing the same characteristic. But whereas the medieval problem focuses on internal sameness in general, the contemporary problem focuses on just one species of such sameness-namely, numerical sameness (or identity). And unlike the previous difference, this one is significant. We can clarify the precise nature of the significance if we restate the medieval problem in a more general form that mirrors our earlier statement of the contemporary problem. To this end, let us rely once again on our earlier definitions of kind and characteristic and replace our definition of universal characteristic with that of a common characteristic:

(3*) Common characteristic $=_{\text {def }}$ a characteristic that is internally the same (but not necessarily identical) for all members of the same kind.

\footnotetext{
${ }^{32}$ See again, e.g., the passage from In Sent 2.17.1.1 cited in $\$ 2$ above.
} 
In that case, we can state the medieval problem, and its solutions, as follows:

\section{The Medieval Problem of Universals-Final Characterization}

The problem:

- Are distinct things members of the same kind in virtue of sharing a common characteristic?

The main solutions:

- Realism $=$ Yes, and hence there are common characteristics.

- Extreme (or robust) realism = common characteristic are universals.

- Moderate realism = common characteristics are individuals.

- Nominalism $=$ No, because there are no common characteristics.

Once the medieval problem is stated in this way, the significance of its difference from the contemporary problem becomes clear from the fact that it admits of very different sorts of solution. In particular, one can be a realist with respect to the medieval problem (because one accepts common characteristics), and yet be nominalist with respect to the contemporary problem (because one rejects universals). Indeed, it is precisely for this reason that it is helpful to distinguish moderate from more extreme (or robust) forms of medieval realism—where this makes next to no sense in the case of contemporary solutions. ${ }^{33}$ On the contrary, in the case of contemporary solutions it makes much more sense to speak of more or less extreme forms of nominalism (depending on whether characteristics are distinct from their bearers or not).

All of this is, of course, directly relevant to the proper classification of Aquinas's views. For it helps us to see that there is no simple answer to the question of whether Aquinas is a realist or a nominalist with regard to the problem of universals. On the contrary, properly understood, he is both. ${ }^{34}$

\footnotetext{
${ }^{33}$ Though see again my remarks about ostrich realism in nn. 5 and 9 above.

${ }^{34}$ Earlier versions of this paper were presented at the 2012 Montreal Workshop in Nominalism, the 2012 Midwest Annual Workshop in Metaphysics, and the 2014 Cornell Summer Colloquium in Medieval Philosophy. I'm grateful to members of the audiences on these occasions for stimulating discussion, comments, and criticism. I'd also like to thank Michael Bergmann, Susan Brower-Toland, James Van Cleve, and Andrew Newman for helpful written comments on earlier drafts of this paper.
} 


\section{REFERENCES}

Armstrong, D. M. 1989. Universals: An Opinionated Introduction. Boulder: Westview Press. . 1979. A Theory of Universals. Cambridge: Cambridge University Press.

Brower, Jeffrey E. 2014. Aquinas's Ontology of the Material World. Oxford University Press: Oxford.

Bulthius, Nathanial E. Forthcoming. "Properties in Walter Burley's Later Metaphysics.” In Responses to Ockham, ed. Christian Rode. Leiden: Brill.

Clark, Ralph W. 1974. “Saint Thomas Aquinas's Theory of Universals,” The Monist 58: 163-72.

Edwards, Sandra. 1985. “The Realism of Aquinas,” New Scholasticism 59: 79-101.

Galluzzo, Gabriele. 2004. "Aquinas on Common Natures and Universals," Recherches de Théologie Et Philosophie Médiévales 71:131-71.

Gracia, Jorge. 1994. "Cutting the Gordian Knot of Ontology: Thomas's Solution to the Problem of Universals.” In Thomas Aquinas and His Legacy, ed. D. Gallagher, 16-36. Washington, DC: Catholic University of America Press.

Guilfoy, Kevin. 2008. "William of Champeaux," The Stanford Encyclopedia of Philosophy (Fall 2008 Edition), Edward N. Zalta (ed.), URL = $<$ http://plato.stanford.edu/archives/fall2008/entries/william-champeaux/>.

Hawthorne, John. 1999. "Scotus on Universals," paper presented at Cornell Colloquium in Medieval Philosophy, Cornell University.

Klima, Gyula. 2013. "The Medieval Problem of Universals," The Stanford Encyclopedia of Philosophy (Fall 2013 Edition), Edward N. Zalta (ed.), URL = $<$ http://plato.stanford.edu/archives/fall2013/entries/universals-medieval/>.

Leftow, Brian. 2003. “Aquinas on Attributes," Medieval Philosophy and Theology 11: 1-41.

Lewis, David. 1983. "New Work for a Theory of Universals," Australasian Journal of Philosophy 61: 343-77.

McInerny, Ralph. 1990. Boethius and Aquinas. Washington, D.C.: Catholic University of America Press.

Oliver, Alex. 1996. “The Metaphysics of Properties,” Mind 105: 1-80.

Owens, Joseph. 1957. "Common Nature: A Point of Comparison between Thomistic and Scotistic Metaphysics,” Mediaeval Studies 19: 1-14. 
Panaccio, Claude. 2011. Ockham on Concepts. Aldershot, UK: Ashgate.

Spade, Paul V. 1999. "Degrees of Being, Degrees of Goodness: Aquinas on Levels of Reality." In Aquinas's Moral Theory: Essays in Honor of Norman Kretzmann, eds. Scott MacDonald and Eleonore Stump, 254-275. NY: Cornell University Press. . 1996. "Boethius against Universals: The Arguments in the Second Commentary on Porphyry." $<$ http://pvspade.com/Logic/docs/boethius.pdf $>$ . 1994, trans. Five Texts on the Medieval Problem of Universals: Porphyry, Boethius,Abelard, Duns Scotus, Ockham. Indianapolis: Hackett. . 1985. Survey of Medieval Philosophy, Version 2. $<$ http://pvspade.com/Logic/docs/Survey\%202\%20Interim.pdf>

Thomas Aquinas. 1882-. S. Thomae Aquinatis Doctoris Angelici Opera Omnia. Rome: Commisio Leonina.

Vols. 4-12: Summa theologiae.

Vols. 25.1-2: Quaestiones de quolibet.

Vol. 43: De ente et essentia.

Vol. 45.1: Sentencia libri De anima.

. 1929-47. Scriptum super libros Sententiarum, ed. P Mandonnet and M. F. Moos. Paris: P. Lethielleux.

van Inwagen, Peter. 2011. "Relational vs. Constituent Ontologies," Philosophical Perspectives 25: 389-405.

Wippel, John F. 2000. The Metaphysical Thought of Thomas Aquinas: From Finite Being to Uncreated Being. Washington, D.C.: The Catholic University of America Press. 